\title{
An Effective Teaching Method to Enhance History-Taking Skills for Chinese Medical Students
}

\author{
Simin Huang ${ }^{1}$, Peng $\mathrm{Xu}^{2}$, Lie Feng ${ }^{1}$, Chunting $\mathrm{Lu}^{3} \&$ Jing Yang ${ }^{1}$ \\ ${ }^{1}$ Department of Internal Medicine, the First Affiliated Hospital of Jinan University, Guangzhou, China \\ ${ }^{2}$ Department of Emergency, the First Affiliated Hospital of Jinan University, Guangzhou, China \\ ${ }^{3}$ The Science \& Education Office, the First Affiliated Hospital of Jinan University, Guangzhou, China \\ Correspondences: Chunting Lu, Department of Emergency, the First Affiliated Hospital of Jinan University, \\ Guangzhou, 510630, China. Tel: 86-20-3868-8038. E-mail: jnuchuntinglu@163.com. \& Jing Yang, Department of \\ Internal Medicine, the First Affiliated Hospital of Jinan University, Guangzhou, 510630, China. Tel: \\ 86-20-3868-8748. E-mail: quincyjingjing@126.com.
}

Received: March 4, 2018

Accepted: March 26, 2018

Online Published: March 27, 2018

doi:10.5430/ijhe.v7n2p144

URL: https://doi.org/10.5430/ijhe.v7n2p144

\begin{abstract}
History taking is an extremely important skill for medical students to master. In China, medical students usually have opportunities to practise this skill on real patients after they have learned diagnostics and basic relevant theoretical knowledge. Today, however, several factors, such as increased enrolment of medical students and the need to ensure patient safety in avoiding stressful doctor-patient relationships may increase both the difficulty and the importance for medical students to develop this skill. In view of these situations, the aim of this study was to introduce one specific teaching method, i.e., role-play activity, in order to help medical students cultivate and practise history-taking and related skills. 52 third-year medical students were divided into two groups. Students in observation group received role-play activity training before interviewing with real patients. Students in control group were taught by traditional methods without the new method intervention. The teaching effects of role-play activities were evaluated via medical records, tests of history taking and theoretical exams, and questionnaire for the observation group. The scores of seven medical case records for each student in the observation group were analysed and were found to be higher than those in the control group. These results showed no significant differences between the two groups in the first and second interview records with real patients in the hospital, but statistically significant differences were found from the third time. The scores on history-taking tests with a standardized patient (SP) were higher in the observation group than in the control group. No significant difference was found between the two groups in their theory exam scores. Results indicated that role-play activity is an effective method for medical students to improve their history-taking skills.
\end{abstract}

Keywords: medical students, history taking, role-play activity, clinical skills, standardized patient, medical education

\section{Background}

History taking is considered a basic clinical skill for clinicians. Data obtained from history taking are essential and important for making an accurate diagnosis (Haring, Cools, van Gurp P, van der Meer, \& Postma, 2017; Jose, 2012). However, this skill is difficult for students to learn and develop in the beginning (McKenna, Innes, French, Streiberg, \& Gilmour, 2011). Lack of time, lack of training and lack of resources are barriers preventing students from improving in this basic skill (Goncalves et al., 2016; Troncon, 2009). Therefore, various teaching methods are introduced to teach students to take a complete medical history. These methods include lectures, using simulated patients, engaging in role-play activity and using videotape to record students' interviews (Keifenheim et al., 2015; Yu et al., 2017).

In China, history taking is taught in the fifth or sixth semester of education for a 5-year or 6-year clinical medicine major (Zhang, Cheng, Xu, Luo, \& Yang, 2015; Pan, Cheng, Zhou, Li, \& Yang, 2016). The current method of teaching history taking in Chinese medical schools mainly includes two parts: theoretical study and bedside practice. Teachers give lectures in the classroom, and then students practise on real patients in the teaching hospital. In our practice, we have found that history taking remains difficult for beginners. The main problems include initially 
feeling nervous about communicating with real patients, lacking communication skills, and forgetting items when taking histories; therefore, students usually become flustered when facing real patients in the ward for the first time.

There are also other factors that may influence improvement in the history-taking curriculum in China. First, increasing numbers of students have entered medical schools in the last decade, indirectly leading to a shortage of teachers and hospital resources (Lian, \& He, 2013). On the other hand, the conflict between doctors and patients in China is a widespread phenomenon (Yao et al., 2014; The Lancet, 2010). It also influences clinical teaching and learning effects. Accordingly, bedside practice with real patients for history taking is recommended to ensure student proficiency and patient safety. Some study data have also suggested that history taking is still a weakness in Chinese medical students' clinical skills. Thus, in the National Clinical Skills Competition, which has been held in China by the Research Center of Clinical Medical Education of the Ministry of Education every year since 2010, history taking is still an essential competence assessed (Jiang et al., 2016). The average score for history taking in the third national clinical skills competition in Hubei division was 4.98 out of 10 points (see e.g., Wang, 2013). In the seventh competition in the South division, the average score for history taking was 5.86 out of 10 points (unpublished data). Consequently, it is necessary to explore a new and effective training method to improve history-taking skills for medical students, even in a small area.

Role-play activity has been widely used to teach and learn history taking in medical schools and has usually been integrated into other pedagogics in order to increase students' comprehensive clinical abilities. Several studies have shown that role play is a very effective method to enhance students' history-taking skills (see e.g., Schweickert, \& Heeren, 1999; Skelton, \& Matthews, 2001; Fitzgerald, Crowley, Greenhouse, Probert, \& Horner, 2003; Wiskin, Roberts, \& Roalfe, 2011). In China, Zhu et al. also used this teaching method in fourth grade students, the results showed that students who accepted the teaching method had higher scores in history taking and medical record writing (see e.g., Zhu, Qiu, Qu, Xue, \& Yan, 2014).

In this study, role-play activity was introduced and implemented in third-year students with a clinical medicine major in order to improve their history-taking and relevant skills. This research explored many new and specific training methods, including doctor and patient roles, evaluator performance, group discussion, clinical scenario settings in combination with real bedside teaching, and teachers' debriefing. Formative and terminal assessments in medical case records and practical history-taking tests were used to assess this new teaching method.

\section{Methods}

\subsection{Participants}

This explorative study was carried out at the First Affiliated Hospital of Jinan University in Guangzhou, located in southern China. After experiencing the basic medical curriculum for 2 years, students in our hospital began the clinical curriculum "Basic Clinical Skills" in their fifth semester of clinical education; this curriculum included chapters on history taking and common symptoms. The main goal of this course is to instruct students to master history-taking items and methods, the diagnostic process and related clinical thinking and definition, aetiology, clinical manifestations, and key points of common symptoms. All students had previously completed basic medical sciences and compulsory courses in doctor-patient communication.

During the academic year 2016-2017, 52 junior medical students were randomized into an observation group (n=25) and a control group ( $\mathrm{n}=27)$.

\subsection{Course Arrangement}

The course consisted of two parts: theoretical study and practical training. The theoretical study portion occurred weekly from the $1^{\text {st }}$ week to the $8^{\text {th }}$ week, totalling 18 teaching hours. The content of this part included history taking and common symptoms. The practical training began in the $6^{\text {th }}$ week, covering 36 teaching hours. Students in both groups were interviewed with real patients in seven different specialties in the internal medicine department. The observation group received specific and additional role-play activity training on history taking before conducting interviews with real patients, whereas the control group followed the traditional teaching method. All clinical knowledge and skills were taught by the same faculty staff team in both the observation group and the control group. The content and arrangement of the theoretical study and practical training are listed in Table 1. 
Table 1. Course outline and arrangement

\begin{tabular}{|c|c|c|}
\hline Contents & Minutes & Teaching methods \\
\hline History Taking & 90 & lecture \\
\hline Fever, Edema, Loss of Body Weight & 90 & lecture \\
\hline Cough and Expectoration, Haemoptysis, Dyspnoea & 90 & lecture \\
\hline Palpitation, Cyanosis, Chest pain & 90 & lecture \\
\hline $\begin{array}{l}\text { Abdominal Pain, } \\
\text { Haematochezia, Jaundice }\end{array} \quad$ Diarrhoea, Haematemesis, & 90 & lecture \\
\hline $\begin{array}{l}\text { Headache, Vertigo, Syncope, Tic and Convulsion, } \\
\text { Disturbance of Consciousness }\end{array}$ & 90 & lecture \\
\hline Mucocutaneous Haemorrhage, Arthralgia & 90 & lecture \\
\hline $\begin{array}{l}\text { Frequent Micturition, Urgent Micturition, Odyuria, } \\
\text { Oliguria, Anuria, Polyuria, Haematuria }\end{array}$ & 90 & lecture \\
\hline History Taking, medical record & 240 & practice and discussion \\
\hline Disease of respiratory system & 240 & practice and discussion \\
\hline Disease of cardiovascular system & 240 & practice and discussion \\
\hline Disease of digestive system & 240 & practice and discussion \\
\hline Disease of endocrine system & 240 & practice and discussion \\
\hline Disease of haematological system & 240 & practice and discussion \\
\hline Disease of nervous system & 240 & practice and discussion \\
\hline
\end{tabular}

\subsection{Educational Intervention}

Specific and additional settings for role-play activities were given to the observation group. Students in the observation group were trained to role-play in history taking before interviewing with real patients.

Six typical and significant clinical cases (chronic obstructive pulmonary disease, acute myocardial infarction, upper gastrointestinal haemorrhage, diabetes mellitus, rheumatoid arthritis and acute pyelonephritis) were selected and designed as scenarios in accordance with the objectives and requirements of the "Basic Clinical Skill" teaching syllabus. After standardization of these cases, they were used to train students in the observation group. Role-play activities were conducted from the $2^{\text {nd }}$ week to the $5^{\text {th }}$ week, totally 4 teaching hours with one hour per week. Two cases were trained in one course.

During the training and role-play process, 3-4 students formed a group. One student acted as a doctor, one acted as a standardized patient (SP) according to the scenarios, and the other 1-2 students serve as evaluator(s) after the teachers introduced the role-play activities. Finally, debriefing was given verbally by peer classmates and teachers, and teachers summarized the methods and key points of history taking at the end of the class.

\subsection{Assessments}

Four items were evaluated after this teaching method was implemented.

\subsubsection{Assessment of Medical Case Records Written by Students}

From the $6^{\text {th }}$ week, both the observation and control groups interviewed real patients in the hospital. In the first beside practice, the teachers helped all students to review the key points of history taking and medical records. After that, each group was subdivided into two groups and guided by the teachers to obtain the history from a real patient. Then, students were evenly divided into 5 small groups, with an average of 5-6 students included after the teachers' demonstration. Each small group took a history from the real patient independently and wrote medical records after class. The teachers were monitoring the students' performance throughout the activity. The standards for grading medical records were established by the researchers according to the content of history taking and the requirements for medical record writing. Two teachers reviewed the medical records according to the checklist (Table 2). An average score for the medical records for each student was calculated. The total score for each medical record was 100. 
Table 2. Evaluation standards for medical records

\begin{tabular}{ll}
\hline Contents & Standard score \\
\hline Data gathering & 6 \\
1. General information & 10 \\
2. Chief complaint & 50 \\
3. History of present illness & 8 \\
4. Past medical history & 5 \\
5. Symptoms' review in each system & 4 \\
6. Personal history & 2 \\
7. Marital history & 2 \\
8. Family history & \\
Format and writing skills & 2 \\
9. Standardized format & 2 \\
10. Medical terminology & 2 \\
11. Legible handwriting & 2 \\
12.The duration of the main complaint is consistent with the & 2 \\
present medical history & \\
14. Logical order & 4 \\
15. Signature & 2 \\
Total & \\
\hline
\end{tabular}

\subsubsection{Practical Tests of History Taking}

A three-station Objective Structured Clinical Examination (OSCE) was conducted for students in the final evaluation. One OSCE station focused on history taking. Each student completed a 10-minute interview with a teacher standardized patient (TSP). Ten scenario cases of different disorders were provided to students, who selected a case randomly. The evaluation standards for history taking are shown in Table 3. 
Table 3. Evaluation standards for history taking

\begin{tabular}{|c|c|}
\hline Contents & Standard score \\
\hline \multicolumn{2}{|l|}{ Commencement of the interview } \\
\hline 1.Greeting of patient and identification & 2 \\
\hline 2. Introduce self and state the purpose for interview & 2 \\
\hline \multicolumn{2}{|l|}{ Total history } \\
\hline 3. General data & 6 \\
\hline 4. Main complaint & 16 \\
\hline 5. Present history & 36 \\
\hline 6. Past history & 6 \\
\hline 7. Symptoms' review in each system & 10 \\
\hline 8. Personal history & 2.5 \\
\hline 9. Marital history & 1.5 \\
\hline 10. Family history & 2 \\
\hline \multicolumn{2}{|l|}{ Communication skill } \\
\hline $\begin{array}{l}\text { 11. Communicated with open-ended and closed-ended questions, } \\
\text { encourage patient to express concerns }\end{array}$ & 3 \\
\hline 12. Ask clear, unambiguous questions, avoid medical jargon & 3 \\
\hline 13. Avoid leading questions and strings of questions & 2 \\
\hline 14. Avoid interrupting the patient & 1 \\
\hline 15. Appropriate eye contact & 1 \\
\hline 16. Place questions in logical order & 2 \\
\hline \multicolumn{2}{|l|}{ Conclusion } \\
\hline 17. Summarize patient's statement & 2 \\
\hline 18. Thank patient and explain the next step & 2 \\
\hline Total & 100 \\
\hline
\end{tabular}

\subsubsection{Theoretical Examination}

At the end of the semester, a theoretical examination that included history-taking and symptomatology-related knowledge was held. The assessment focused on students' mastery of basic definitions, understanding and abilities, and flexible analysis of clinical problems. The paper included four major parts: medical terms (10\%), filling in the blanks (10\%), single-best-answer multiple choice questions (50\%), and long questions and case analysis (30\%). The total score was 100. Standard answers and scoring criteria for all questions were established based on reference textbooks. Teachers' evaluation of the papers was blinded and objective.

\subsubsection{Feedback Questionnaire}

A feedback questionnaire was given to evaluate this teaching method. After the final examination, students in the observation group were asked to fill in a brief questionnaire about their perceptions of this teaching method and their satisfaction. The questionnaire consisted of 6 questions based on dichotomous responses (yes/no).

\section{Ethics Approval and Consent to Participate}

The practice component is a part of the course. Our intervention was non-invasive and had no influence on patients. Therefore, ethical approval was not needed.

All students in the observation group were provided with written information about the study and informed that they could withdraw at any time. Students signed informed consent forms and a confidentiality agreement. 


\section{Statistical Analysis}

Analysis was performed using SPSS version 16.0. Qualitative data were expressed as numbers and percentages. Quantitative data were expressed as the means and standard deviations (SDs). The baseline characteristics, scores for medical records and examinations of the two groups were compared by using a $t$-test. Categorical variables were compared using the Pearson chi square test. Significance was defined at $P<0.05$.

\section{Results}

\subsection{Basic Characteristics of Students}

There were 13 male and 12 female students and 12 male and 15 female students in the observation and control groups, respectively. There was no significant difference in the distribution of gender between these two groups $\left(\chi^{2}=\right.$ $0.297, P=0.586)$.

In terms of mean age, score for doctor-patient communication and the grade points for first-year and second-year between the observation group and control group, the differences were not statistically significant $(P=0.982, P=$ $0.167, P=0.941$ and $P=0.314$, respectively). The basic characteristics of the students are shown in Table 4 .

Table 4. Basic characteristics of students

\begin{tabular}{llll}
\hline & $\begin{array}{l}\text { Observation group } \\
(\mathrm{n}=25)\end{array}$ & $\begin{array}{l}\text { Control group } \\
(\mathrm{n}=27)\end{array}$ & P value \\
\hline Male/Female & $13 / 12(52 \% / 48 \%)$ & $12 / 15(44.4 \% / 55.6 \%)$ & 0.568 \\
Age of doctor-patient & $21.61 \pm 0.70$ & $21.64 \pm 0.81$ & 0.982 \\
Score & $87.5 \pm 3.96$ & $84 \pm 4.80$ & 0.167 \\
communication & & & \\
Grade point & & & \\
First-year & $2.95 \pm 0.41$ & $2.99 \pm 0.55$ & 0.941 \\
Second-year & $2.78 \pm 0.56$ & $3.06 \pm 0.57$ & 0.314 \\
\hline
\end{tabular}

5.2 Comparison of the Two Groups' Results in Medical Records and Examinations

The scores for medical records in the observation group were higher than those in the control group. However, there were no significant differences between these two groups in their first and second interviews with real patients $(P=$ 0.083 and $P=0.158$, respectively). From the third to the seventh interviews, differences were found between the two groups (Table 5 and Figure 1).

Compared to the score for the control group $(72.05 \pm 12.08)$, the score for history taking with TSP in the observation group was higher $(79.34 \pm 9.43)$. A statistical difference was found between the two groups $(P=0.007)$ (Table 5 and Figure 2).

Comparison of theory examination result showed that the score in the observation group $(74.06 \pm 5.66)$ was higher than that in the control group $(69.88 \pm 10.98)$. However, the difference between the two groups was not significant $(P$ $=0.054$ ) (Table 5 and Figure 3).

Table 5. Comparison of the two groups' results in medical records and examinations

\begin{tabular}{llll}
\hline Contents & Observation group $(\mathbf{n}=\mathbf{2 5})$ & Control group $(\mathbf{n}=\mathbf{2 7})$ & $\boldsymbol{P}$ value \\
\hline Medical records & & & \\
1 & $61.93 \pm 12.79$ & $56.87 \pm 11.80$ & 0.083 \\
2 & $66.39 \pm 7.01$ & $63.62 \pm 9.29$ & 0.158 \\
3 & $68.33 \pm 10.68$ & $61.88 \pm 12.28$ & 0.026 \\
4 & $70.90 \pm 7.66$ & $64.32 \pm 7.57$ & 0.001 \\
5 & $71.62 \pm 5.50$ & $66.06 \pm 5.75$ & 0.008 \\
6 & $78.37 \pm 4.45$ & $68.48 \pm 4.60$ & 0.000 \\
7 & $82.53 \pm 4.44$ & $74.24 \pm 5.54$ & 0.000 \\
History taking & $79.34 \pm 9.43$ & $72.05 \pm 12.08$ & 0.007 \\
Theory examination & $74.06 \pm 5.66$ & $69.88 \pm 10.98$ & 0.054 \\
\hline
\end{tabular}




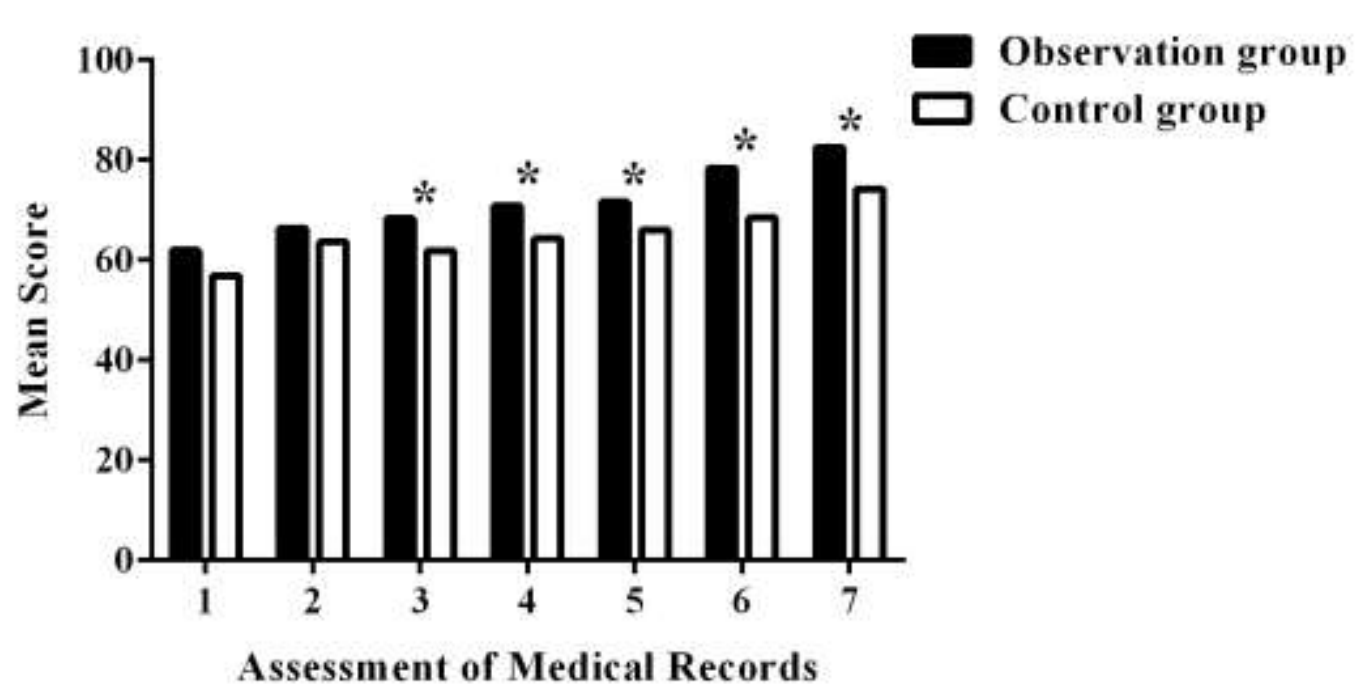

Figure 1. Comparison of the two groups' results in the medical records $\left({ }^{*} p<0.05\right)$.

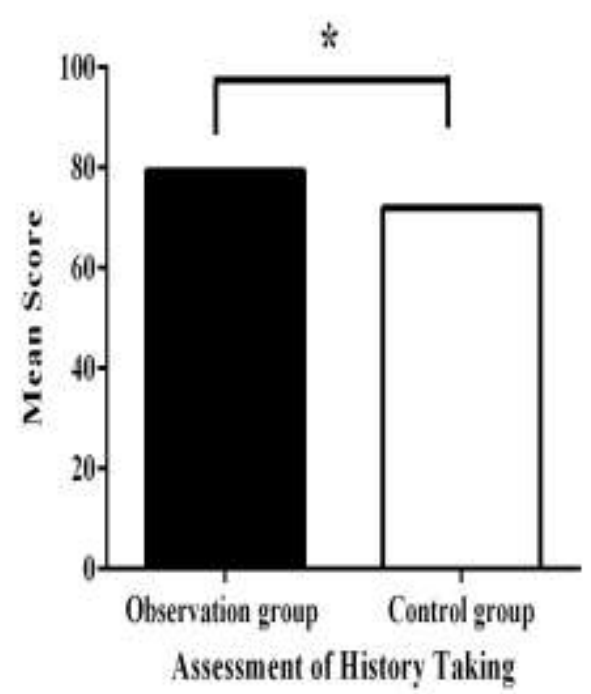

Figure 2. Comparison of the two groups results in the examination of history taking $\left({ }^{*} p<0.05\right)$.

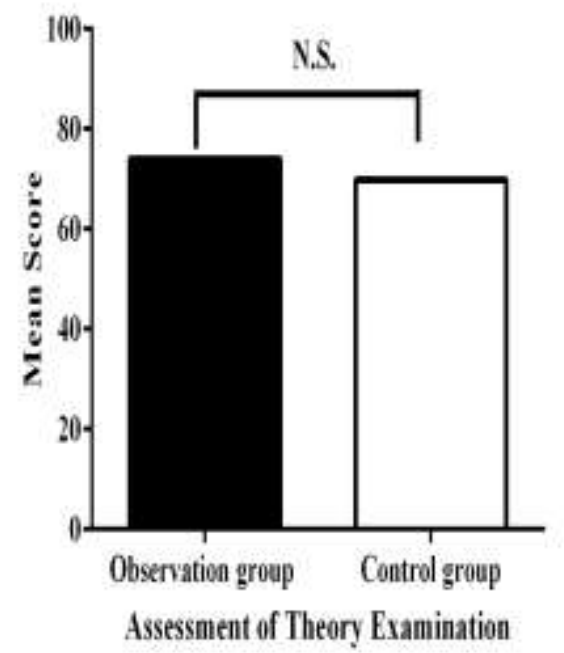

Figure 3. Comparison of the two groups' results in the examination of theory

(N.S.: No significance).

\subsection{Questionnaire of Students' Evaluation}

From the questionnaire, students expressed that the role-play activity was helpful for training on history taking. Specifically, 96\% (24/25) of the students stated that the activity improved their history-taking skills, and 92\% (23/25) of the students stated that this activity increased their confidence in communicating with real patients. They considered the role-play activity to be an effective way to learn history taking, and they were interested in this teaching method. The role-play activity also increased students' motivation to study history, including $84 \%$ (21/25) of the students. Eighty percent (20/25) of them reported that the activity increased their ability to write medical records. More details from the questionnaire are illustrated in Figure 4. 


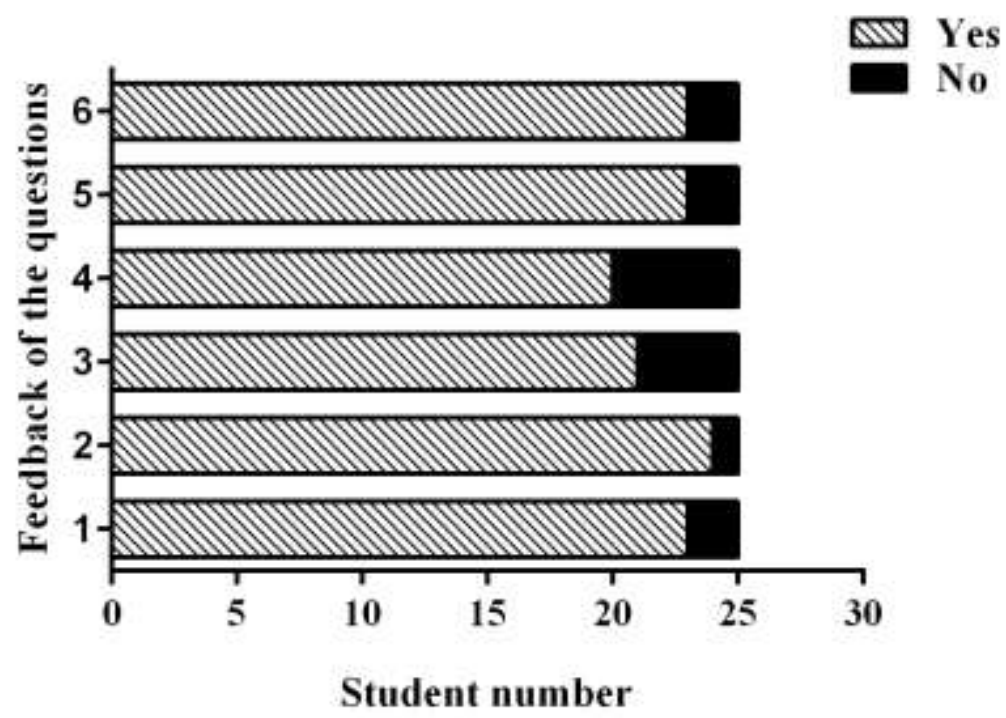

Figure 4. The questionnaire on students' evaluation.

1-6: The bar charts showed the questionnaire results about the following questions. (1) The activity increases my confidence to communicate with real patients. (2) The activity improves my history taking skills. (3) The activity increases my motivation to study history taking. (4) The activity increases my ability to write medical records. (5) I consider this method to be an effective learning style. (6) I am interest in this teaching method.

\section{Discussion}

In this study, role-play activity was introduced and explored to train medical students in history taking in a practical course. The teaching effects were satisfactory based on the assessment of medical case records written by the students, history-taking tests and questionnaire feedback investigations. The scores for medical records and practical tests of history taking on SP were higher in the observation group than in the control group. These results indicated that the role-play activity was an effective teaching method for students to collect clinical data and communicate with patients.

History taking is one of the most important clinical skills to teach and assess in medical education (Dare, Cardinal, Kolbe, \& Bagg, 2008). Studies have proven that history-taking and interview skills should be trained using effective teaching methods (see e.g., Peltier et al., 2007; Losh et al., 2005; Von Lengerke, Kursch, Lange, \& APG-Lehrteam, 2011). Methods for assessing these teaching progress have included the OSCE, questionnaires, interviews with SP or real patients, written examination and so on (Keifenheim et al., 2015; Yu et al., 2017). In this study, the ability to gather data and communicate with real patients was emphasized and cultivated in an authentic way. Multi-level indexes were used to evaluate the role-play activity and teaching effects.

Medical case records were first evaluated because they are considered to be very important materials for clinical teaching and research. Furthermore, it's a very important evidence in medical disputes (Liu, 2014). The quality of medical records is one of the methods for evaluating teaching effectiveness in clinical internship (Ma, \& Zhang, 2013). This study showed that the scores for the medical records in the observation group were higher than those in the control group. In particular, the scores in the observation group were significantly higher than those in the control group from the third to the seventh interviews with real patients for history taking. No significant differences were found in the first and second interviews in bedside practice. The reason for this result is that some time was needed even for the observation group to master and adapt history-taking skills because real patient illnesses were complicated and changeable. However, the observation group took less time to collect complete and definitive data and communicated with real patients more smoothly.

Second, the scores for practical history-taking tests with TSP in the final examination were also higher in the observation group than in the control group. This result implied that students mastered the content and skills of history taking better after having received role-play activity training. The result demonstrated that this new and specific activity was effective in improving history-taking skills for medical students. Troncon (2009) implemented 
role-play activity to increase students' motivation to study history taking. Students benefited from this programme; a few students even perceived that the role-play activity greatly improved their techniques before they interviewed real patients.

Several other studies also introduced a role-play activity to practise history-taking and communication skills. These projects were usually combined with interviewing SP and real patients. Feedback and discussion were provided by group members and staff. Evans, Coman, and Goss (1996) evaluated specialized consulting skills training by using a role-play activity and SP. The results showed that trained students had significantly better communication, problem processing and summary skills. Mukohara et al. (2004) implemented a two-day seminar on medical interview and communication skills; in this study, students in the intervention group reviewed a trigger videotape of the doctor-patient encounter and then practised these skills via role play and videotape review. Differences were found between the intervention group and control group in the ability to "explore how the problem affects the patient's life". Eoaskoon, Sumawong, and Silpakit (1996) conducted SP interviews, role play and feedback to assess the effect of training in history taking. The result of questionnaire indicated that the program was useful for students. In a study about medical interviewing skills (Novack, Dube, \& Goldstein, 1992), students practised new skills by using a role-play activity, and they used these skills with friends, family and others. Then, students had opportunities to practise with patients. In fact, role-play activity is widely used for improving history-taking and communication skills. Such activity is effective for medical students, especially when combined with other teaching methods.

In our study, the theoretical examination scores were higher in the observation group than in the control group, but the difference was not significant. One possible reason is that all of the content of the theoretical examination was from books and lectures. In contrast to practice, a theoretical examination mainly depends on memory, whereas history taking is closely related to the situation, the attitudes of patient and doctor, patient's cultural background, patient's education degree and other factors (Keifenheim et al., 2015). This finding also showed that more skills were needed in communicating with real patients.

The results of the questionnaire about students' evaluations of this teaching method were satisfactory for a majority of the students who benefitted from this research. The results revealed high student satisfaction with this method. The activity can increase students' confidence and skills in communicating with real patients. The role-play activity increased their motivation to study history taking. It is an effective strategy to learn history taking, and they were interested in this teaching method.

There are a few limitations of this study. First, in this study, debriefing was given verbally only from peer classmates and faculty staff and mainly depended on direct observation. When time is limited, short, immediate feedback following by direct observation seems to be the most suitable format (Perron et al., 2016). However, some researchers have indicated that feedback based on audiotaped and/or videotaped reviews is superior to verbal feedback alone in the context of communication skills and clinical reasoning (see e.g., Novack, Dube, \& Goldstein, 1992; Perron et al., 2016; Ozcakar et al., 2009). A study from Novack, Dube, and Goldstein (1992) reported that the use of audiotaped and videotaped reviews enhanced the learning experience of students. In terms of discussion of clinical reasoning, communication and history taking skills, videotaped interviews and feedbacks were more useful to improve clinical skills (Perron et al., 2016; Ozcakar et al. 2009). We may thus consider introducing videotaped and audio-recording in future research. Second, during practice with real patients, we did not have enough teachers to follow the procedures. We evaluated the results only by considering medical records. If we could evaluate the process of each student, suggestions for students could be given more accurately. Third, in regard to the questionnaire, the questions were all closed-ended, and only two answers were given to choose from, which did not allow much flexibility to identify students' opinions. If rating scales had been used instead of dichotomous responses, then the questionnaire data could have provided a better understanding of the participants.

\section{Conclusion}

This study showed that students who engaged in a role-play activity had higher scores in medical case records assessment and practical tests of history taking on SP. Students in the observation group were more skilful in their data gathering and interview performance in the hospital. The role-play activity enhanced students' confidence in communicating with real patients. It was an effective method for medical students to improve their history-taking skills. In the future, more typical and significant teaching cases will be collected and designed for medical students to practise history-taking skills by using role-play activity.

\section{Competing interests}

The authors declare that they have no competing interests. 


\section{Acknowledgements}

The authors would like to thank all of the teachers from different specialties in the internal medicine department and the medical students who participated in this study.

\section{Funding source}

This study was supported by the teaching research programmes of higher medical education of the Ministry of Education in 2016 (grant number: Edu-CR-2016-4-2); the Guangdong Province project for the pedagogical reform of higher education in 2016; and the 18th research project for pedagogical reform at Jinan University (grant number: JG2016028).

\section{References}

Dare, A.J., Cardinal, A., Kolbe, J., \& Bagg, W. (2008). What can the history tell us? An argument for observed history-taking in the trainee intern long case assessment. New Zealand Medical Journal, 121(1282), 51-57. https://www.researchgate.net/publication/23280864

Evans, B.J., Coman, G.J., \& Goss, B. (1996). Consulting skills training and medical students' interviewing efficiency. Medical Education, 30(2), 121-128. https://doi.org/10.1111/j.1365-2923.1996.tb00729.x

Eoaskoon, W., Sumawong, V., \& Silpakit, C. (1996). Evaluation of training medical students in patient-interviewing skills by three modes of learning. Journal of the Medical Association of Thailand, 79(8), 526-530. https://www.researchgate.net/publication/14349084

Fitzgerald, M., Crowley, T., Greenhouse, P., Probert, C., \& Horner, P. (2003). Teaching sexual history taking to medical students and examining it: experience in one medical school and a national survey. Medical Education, 37(2), 94-98. https://doi.org/10.1046/j.1365-2923.2003.01411.x

Goncalves, L.M., Osorio, H.S., Oliveira, L.L., Simonetti, L.R., dos Reis, E., \& Lucchetti, G. (2016). Learning from listening: helping healthcare students to understand spiritual assessment in clinical practice. Journal of Religion \& Health, 55(3), 986-999. https://doi.org/10.1007/s10943-015-0146-y

Haring, C.M., Cools, B.M., van Gurp, P. J.M., van der Meer, J.W.M., \& Postma, C.T. (2017). Observable phenomena that reveal medical students' clinical reasoning ability during expert assessment of their history taking: a qualitative study. BMC Medical Education, 17, 147. https://doi.org/10.1186/s12909-017-0983-3

Jose, J. A. (2012). History taking. Work, 41(Suppl 1), 5369-5370. http://dx.doi.org/10.3233/WOR-2012-0081-5369

Jiang, G.C., Chen, H., Wang, Q.M., Chi, B.R., He, Q.N., Xiao, H.P., et al. (2016). National Clinical Skills Competition: an effective simulation-based method to improve undergraduate medical education in China. Medical Education online, 21, 29889. https://doi.org/10.3402/meo.v21.29889

Keifenheim, K.E., Teufel, M., Ip, J., Speiser, N., Leehr, E.J., Zipfel, S., et al. (2015). Teaching history taking to medical students: a systematic review. BMC Medical Education, 15, 159. https://doi.org/10.1186/s12909-015-0443-x

Lian, J.Q., \& He, F.T. (2013). Improved performance of students instructed in a hybrid PBL format. Biochemistry \& Molecular Biology Education, 41(1), 5-10. https://doi.org/10.1002/bmb.20666

Losh, D.P., Mauksch, L.B., Arnold, R.W., Maresca, T.M., Storck, M.G., Maestas, R.R., et al. (2005). Teaching inpatient communication skills to medical students: an innovative strategy. Academic Medicine, 80(2), 118-124. https://doi.org/10.1097/00001888-200502000-00002

Liu, X. (2014). Study on legal assessment of medical record. Evidence Science, 22, 325-345.

McKenna, L., Innes, K., French, J., Streiberg, S., \& Gilmour, C. (2011). Is history taking a dying skill? An exploration using a simulated learning environment. Nurse Education in Practice, 11(4), 234-238. https://doi.org/10.1016/j.nepr.2010.11.009

Ma, Y.B., \& Zhang, Y. (2013). Research and evaluation of the teaching method of medical records writing in clinical internship. Chinese Medical Record, 14, 56-58.

Mukohara, K., Kitamura, K., Wakabayashi, H., Abe, K., Sato, J., \& Ban, N. (2004). Evaluation of a communication skills seminar for students in a Japanese medical school: a non-randomized controlled study. BMC Medical Education, 4, 24. https://doi.org/10.1186/1472-6920-4-24

Novack, D.H., Dube, C., \& Goldstein, M.G. (1992). Teaching medical interview. A basic course on interviewing and 
the physician-patient relationship. Archives of Internal Medicine, 152(9), 1814-1820. https://doi.org/10.1001/archinte.1992.00400210046008

Ozcakar, N., Mevsim, V., Guldal, D., Gunvar, T., Yildirim, E., Sisli, Z., et al. (2009). Is the use of videotape recording superior to verbal feedback alone in the teaching of clinical skills? BMC Public Health, 9, 474. https://doi.org/10.1186/1471-2458-9-474

Pan S. Q., Cheng X., Zhou Y. H., Li K., \& Yang X. S. (2016). Seeking the optimal time for integrated curriculum in Jinan University School of Medicine. International journal of higher education, 6(1), 25-33. https://doi.org/10.5430/ijhe.v6n1p25

Peltier, D., Regan-Smith, M., Wofford, J., Whelton, S., Kennebecks, G., \& Carney, P.A. (2007). Teaching focused histories and physical exams in ambulatory care: a multiinstitutional randomized trial. Teaching and Learning in Medicine, 19(3), 244-250. https://doi.org/10.1080/10401330701366465

Perron, N.J., Louis-Simonet, M., Cerutti, B., Pfarrwaller, E., Sommer, J., \& Nendaz, M. (2016). Feedback in formative OSCEs: comparison between direct observation and video-based formats. Medical Education Online, 21, 32160. https://doi.org/10.3402/meo.v21.32160

Schweickert, E.A., \& Heeren, A.B. (1999). Scripted role play: A technique for teaching sexual history taking. Journal of the American Osteopathic Association, 99(5), 275-276. https://doi.org/10.7556/jaoa.1999.99.5.275

Skelton, J.R., \& Matthews, P.M. (2001).Teaching sexual history taking to health care professionals in primary care. Medical Education, 35(6), 603-608. https://doi.org/10.1046/j.1365-2923.2001.00926.x

Troncon, L.E. (2009). Structured, three-way, role-play activity for improving history-taking skills. Medical Education, 43(11), 1097. https://doi.org/10.1111/j.1365-2923.2009.03484.x

The Lancet. (2010). Chinese doctors are under threat. Lancet, 376(9742), 657. https://doi.org/10.1016/S0140-6736(10)61315-3

Von Lengerke, T., Kursch, A., Lange, K., \& APG-Lehrteam, M.H.H. (2011).The communication skills course for second year medical students at Hannover Medical School: An evaluation study based on students' self-assessments. GMS Zeitschrift fur medizinische Ausbildung, 28(4), Doc54. http://dx.doi.org/10.3205/zma000766

Wang, Y.T. (2013). Analysis and assessment of clinical skills competition (Hubei division) for medical students in medical colleges and universities. China higher medical education, 5, 34-36.

Wiskin, C., Roberts, L., \& Roalfe, A. (2011). The impact of discussing a sexual history in role-play simulation teaching on pre-clinical student attitudes towards people who submit for STI testing. Medical Teacher, 33 (6), e324-332. https://doi.org/10.3109/0142159X.2011.575902

Yu, M.X., Jiang, X.Y., Li, Y.J., Shen, Z.Y., Zhuang, S.Q., \& Gu, Y.F. (2017). Evaluation of medical record quality and communication skills among pediatric interns after standardized parent training history-taking in China. Medical Teacher, 6, 1-5. https://doi.org/10.1080/0142159X.2017.1395833

Yao, S.K., Zeng, Q., Peng, M.Q., Ren, S.Y., Chen, G., \& Wang, J.J. (2014). Stop violence against medical workers in China. Journal of Thoracic Disease, 6(6), E141-145. http://dx.doi.org/10.3978/j.issn.2072-1439.2014.06.10

Zhang M.Y., Cheng X., Xu A.D., Luo L.P., \& Yang X.S. (2015). Clinical simulation training improves the clinical performance of Chinese medical students. Medical education online, 20(13), 157-170. https://doi.org/10.3402/meo.v20.28796

Zhu, L.L., Qiu, L.H., Qu, L., Xue, M., \& Yan, L. (2014). Applicaion of role-play simulation in pre-clinical practice of the fourth grade students in department of endodontics. Shanghai Kou Qiang Yi Xue, 23(5), 634-637. http://europepmc.org/abstract/MED/25543614 